\title{
La sequera de 1817 a Catalunya. \\ Abast i conseqüències socials en un context de postguerra
}

\author{
The drought of 1817 in Catalonia. Scope and social \\ consequences in a post-war context
}

\author{
Carlos Moruno Moyano
}

\section{Resum}

El present article pretén aprofundir en l'estudi del Sexenni Absolutista (1814-1820) a Catalunya i analitzar la sequera que hi va haver en aquest període a partir d'un conjunt de fonts documentals i una abundant bibliografia en gran part provinent de la climatologia històrica. Mitjançant l'estudi d'algunes de les principals ciutats de Catalunya - com Barcelona, Tarragona i Girona- es presenta un període d'eucaristia de pluges que les mateixes fonts defineixen com el més greu des del 1788. També s'analitza la gestió de les autoritats davant la falta d'aigua i l'arribada a les ciutats d'importants grups de camperols que van abandonar les seves terres i hi van anar en busca de beneficència. Aquest va ser el cas de la regió de l'Urgell, que, com veurem, va ser una de les més castigades durant aquest període, en el qual es van succeir sequeres i males collites que van acabar desencadenant una crisi de subsistència que tingué importants expressions al llarg de l'any 1817.

Paraules clau: Sexenni Absolutista (1814-1820), història del clima, història local, Catalunya.

\begin{abstract}
This article examines the context of crisis experienced during the Absolutist Sexennium (1814-1820), focusing on study of the drought of this period in Catalonia, from a set of documentary sources and an abundant bibliography largely from historical climatology. Looking at some of the main cities of Catalonia, such as Barcelona, Tarragona and Girona,

1. ORCID: 0000-0001-5313-9805, Universitat Rovira i Virgili, Tarragona. Adreça electrònica: carlos.moruno@urv.cat. Becari predoctoral FI-AGAUR 2019. URV-ISOCAC. Aquesta publicació ha estat possible gràcies al suport de la Secretaria d'Universitats i Recerca del Departament d'Empresa i Coneixement de la Generalitat de Catalunya, de la Unió Europea i del Fons Social Europeu (2019FI B 00454).

Rebut: IX/2020. Avaluat: X/2020. Versió definitiva: XII/2020.
\end{abstract}


we analyze a eucharistic period of rain that the sources themselves define as the most significant since 1788. Moreover, we study the authorities' management of water shortages and the arrival of large groups of peasants, who abandoned their lands and came to the cities in search of charity, as was the case in the Urgell region, which, as we will see, was one of the most punished during this period of droughts and bad harvests, which triggered a subsistence crisis in 1817 .

Keywords: Absolutist Sexennium (1814-1820), climate history, local history, Catalonia.

\section{Introducció}

La crisi de l'Antic Règim a Espanya (1808-1833) sempre ha generat un gran interès ${ }^{2}$ a causa de les importants transformacions polítiques, econòmiques i socials que s'hi van produir i que van representar la fi de la monarquia absoluta i la irrupció del liberalisme. Els períodes d'irrupció liberal com la Guerra del Francès (1808-1814) o el Trienni Liberal (1820$1823)^{4}$ han donat lloc a un gran nombre de publicacions, mentre que les restauracions del Sexenni Absolutista (1814-1820) i la Dècada Ominosa (1823-1833)5 no han gaudit de la mateixa atenció. Considerem que, a causa de la manca d'estudis referents al Sexenni Absolutista, s'ha tendit a simplificar la crisi econòmica pròpia d'aquest període, que s'ha justificat amb la destrucció i la desarticulació ocorreguda durant la Guerra del Francès. Sense negar l'evident impacte de la guerra, en aquest article presentem altres fenòmens que van contribuir a agreujar aquesta crisi, com la sequera que es va produir durant aquesta època. Les darreres investigacions han identificat un període de sequeres reiterades, també conegut com a megadrought, entre els anys 1812 i 1825 (Pometti 2020; Barriendos, Prohom i Sánchez Lorenzo 2010). Pel que fa al Sexenni Absolutista i tal com indiquen les fonts consultades, aquest procés de sequeres i anys de males collites desencadenà un episodi de crisi de subsistència durant l'any 1817. En el present article ens centrarem a estudiar les conseqüències socials d'aquest fenomen per tal d'intentar copsar quina va ser la seva incidència en aquest context de crisi.

Les fonts emprades han estat les actes municipals de tres de les ciutats més importants de Catalunya (Girona, Barcelona i Tarragona), que han permès identificar les rogatives pro pluvia i comprovar la resposta de les autoritats a la sequera i les diverses consequiències socials que se'n derivaren. Tanmateix, s'ha consultat la correspondència de la Companyia de Cortadelles ${ }^{6}$ en un intent d'aportar un altre punt de vista propi d'una companyia de co-

2. Destacaríem Artola (1959 i 1968), Fontana (1979), Rújula (1998) i La Parra (2018).

3. Sauch (2011), Moliner Prada (2007), Fontana (2008), Arnabat (2013).

4. Gil Novales (1980), Fontana (1961), Torras (1976), Arnabat (2001), Roca (2011).

5. Un dels historiadors que sempre va defensar la necessitat de conèixer millor ambdós períodes va ser Josep Fontana (1971, 1973, 2006). París (2016), Luis (2002).

6. Aquesta documentació es troba al fons de la Companyia d'Aragó, a l'Arxiu Històric de Tarragona. Aquest fons recull documentació de diverses companyies associades i amb vinculacions entre si des de 1730 fins a 1850, entre les quals 
merç. Com veurem, la consulta d'aquest fons ens ha permès identificar les greus conseqüències derivades de la pèrdua de les collites a l'Urgell.

\section{La crisi climàtica de principis del segle xix. Alguna cosa més que unes simples sequeres}

La climatologia històrica ha mostrat un gran interès en l'estudi de les anomalies climàtiques d'aquest període i ha aportat estudis que demostren que aquest període va ser excepcionalment fred i sec, especialment els anys 1815-1818 (Trigo et al. 2009; DomínguezCastro et al. 2012).

Durant el primer terç del segle xix hi va haver un període de baixa activitat solar conegut com el mínim de Dalton (1790-1830). Aquest fenomen s'emmarca dins de la coneguda com a petita edat de gel, que situem entre principis del segle xIv i mitjan segle xIx, i en què es van donar períodes especialment freds, el més important dels quals fou el mínim de Maunder (1645-1715). ${ }^{7}$

El cas del mínim de Dalton és especialment singular, ja que aquest període de baixa activitat solar va coincidir amb una època de gran activitat volcànica. ${ }^{8}$ Durant aquests anys, concretament l'abril del 1815, es va produir una de les erupcions volcàniques més potents de l'últim millenni, la del volcà Tambora (Indonèsia), que va originar el que es coneix com a «any sense estiu» de 1816, amb unes temperatures inusualment baixes (Harington 1992). Amb un índex d'explosivitat volcànica (VEI en anglès) de 7 en una escala de 8, l'erupció va tenir unes conseqüències globals. ${ }^{9}$ Conservem descripcions dels seus efectes en diferents punts de l'hemisferi nord, com a Mont-real i la ciutat de Quebec, on va nevar a principis de juny. El mateixa va passar en zones dels estats de Connecticut i de Nova York, on també es van produir nevades que van inaugurar un període especialment fred de tres mesos que va fer malbé bona part de les collites. En el cas d'Europa, l'estiu del 1816 va ser el més fred des de, com a mínim, l'any 1750 i es va situar entre 1 i $2{ }^{\circ} \mathrm{C}$ per sota de la mitjana del període 1810-1819 (Oppenheimer 2003). Fins i tot hi ha estudis de reconstrucció dendroclimatològica que han confirmat aquest estiu excepcionalment fred a banda i banda de l'Atlàntic (Briffa, Schweingruber i Osborn 1998).

\footnotetext{
la Companyia d'Aragó és la més important i la que va tenir més continuïtat. La seva activitat se centrava en productes agraris i en l'arrendament de drets senyorials; vegeu Sales (1983).

7. Els efectes d'aquests episodis poden variar segons la regió. Per exemple, el mínim de Maunder va desencadenar precipitacions abundants i regulars a la península Ibèrica, mentre que a Mèxic va originar un període de sequeres recurrents. Garza i Barriendos (1998).

8. Confirma aquest fet, per exemple, l'augment de la concentració de diòxid de carboni a partir de 1790: Wagner i Zorita (2005). Vegeu un llistat de les principals erupcions volcàniques d'aquest període a Fisher et al. (2007).

9. Els gasos volcànics s'estableixen a l'estratosfera i creen un filtre que redueix la radiació solar que arriba a la superfície terrestre, cosa que origina un refredament global. Depenent de les dimensions de l'erupció, aquest efecte pot durar fins a tres anys; vegeu Fisher et al. (2007).
} 
La consulta de la documentació de la Companyia de Cortadelles ens ha permès identificar notícies sobre anomalies climàtiques a Catalunya durant aquest sexenni. A principis de 1815 diferents corresponsals de la Companyia es desitjaven bona salut davant uns freds que definien com a extraordinaris en llocs com Solivella o Xerta, a $50 \mathrm{~km}$ de la costa i a la província de Tarragona. La mateixa situació es descrivia a l'interior de Barcelona, en poblacions com Cardona o Vic, on gelava contínuament. ${ }^{10} \mathrm{Ja}$ durant el mes d'abril es mostrava una gran preocupació pels danys que podia causar el fred continuat a les vinyes del Priorat. ${ }^{11} \mathrm{Un}$ informe posterior del mes de maig suavitzava els efectes del fred, que, encara que va acabar danyant les vinyes, no va afectar tant els cultius d'oliva i gra. ${ }^{12}$ Poc després, en una carta enviada als socis de la Companyia a Londres es descriu la situació de la manera següent:

Los fríos tardanos han hecho bastante daño en los sembrados y muchísimo en las viñas. De lo general nos resultará en Aragón y Cataluña menos que mediana cosecha de granos que estaba muy bien preparada, y cortísima la de vino. ${ }^{13}$

Com s'explica en la missiva, aquesta situació es va veure agreujada per la prohibició d'importar gra de França durant la restauració dels Cent Dies. Són diverses les cartes que descriuen la mala collita de grans recollida en bona part de la Península i que es va intentar compensar amb importacions d'altres llocs tan distants com els Estats Units. Uns mesos més tard, durant el mes de novembre, es recomanaria paralitzar les obres d'un magatzem que s'estava construint a Tarragona per por que l'estructura quedés afectada a causa de les contínues gelades que s'estaven produint, recordem, en una ciutat de costa. ${ }^{14}$

A Mallorca també conservem relats que descriuen un estiu inusualment fred durant l'any 1816, fins al punt de retardar la collita del blat fins a finals de juliol «perquè no hi havia sol i estava boirós tot el dia i clar tota la nit, tot un oposat del que es necessitava» (Trigo et al. 2009: 103). En el cas de Catalunya, el baró de Maldà va descriure amb sorpresa la gran quantitat de neu que hi havia als Pirineus, o com el riu Llobregat es va congelar en plena tardor (Barriendos 1996: 92). A més a més, definia les temperatures que hi havia a Barcelona el 18 d'agost com si fossin les pròpies del mes d'abril. Com dèiem, l'estudi dels efectes de l'erupció del volcà Tambora ha estat un tema de debat recurrent en el camp de la climatologia històrica, on diversos treballs plantegen que aquesta erupció va ser la causa principal d'un descens de fins a $2{ }^{\circ} \mathrm{C}$ a la península Ibèrica. ${ }^{15}$

10. Arxiu Històric de Tarragona (AHT), Companyia d'Aragó (CA), Cartes, 1815, f. 70-86.

11. AHT, CA, Cartes, 1816, f. 346-347.

12. AHT, CA, Cartes, 1816, f. 393.

13. AHT, CA, Cartes, 1816, f. 411.

14. AHT, CA, Cartes, 1816, f. 1001.

15. Els efectes d'una erupció volcànica poden variar segons la regió, i encara més en una localització amb una orografia tan accidentada com la península Ibèrica. Hi ha estudis que proposen un descens de $2{ }^{\circ} \mathrm{C}$ al nord-est peninsular i una franja d'entre $1,2 \mathrm{i} 2{ }^{\circ} \mathrm{C}$ per a la resta de la Península (Briffa, Osborn i Schweingruber 2004). Altres estudis plantegen que aquest descens podria haver estat encara més important (Trigo et al. 2009: 112). Aquests efectes, per exemple, també van ser dispars a l'Amèrica del Nord, ja que van ser més importants a la costa est que a l'oest (Lough 1992). 
A la resta d'Espanya els estudis climatològics basats en els registres de rogatives conclouen en una mateixa direcció: que es van produir importants sequeres, encara que distribuïdes de manera desigual pel territori peninsular, entre 1815 i 1818, si bé el fenomen va ser especialment important durant l'any 1817 (Trigo et al. 2009: 103).

\section{Les rogatives pro pluvia de 1817}

Són diversos els estudis que ens permeten afirmar que aquesta sequera va tenir un gran impacte i va ser un fenomen generalitzat a tot Catalunya. Si ens centrem en les rogatives, sabem que van ser recurrents en poblacions distants com Vilafranca del Penedès (Arnabat 2004: 31), Lleida (Sánchez Carcelén 2007: 157), Alcover (Grau i Pujol 1990: 16) o Mataró (Forn i Salvà 1997: 131). ${ }^{16}$

En el cas de Tarragona, la primera notícia sobre la falta d'aigua es va donar a principis de febrer, quan el gremi de pagesos va sollicitar rogatives a la Verge de la Misericòrdia. ${ }^{17}$ El dia 9 es va decidir apellar al Crist de Sang i finalment s'anuncià la seva sortida en processó a finals de mes. ${ }^{18}$ La pluja continuava sense fer acte de presència i el 3 de març es va decidir traslladar la Mare de Déu de la Misericòrdia a l'altar major de la catedral. El dia 10 el gremi de pagesos va sollicitar que se sortís en processó amb el braç de santa Tecla, fet que únicament es produïa en situacions de gran necessitat. ${ }^{19}$

El dia 21 d'abril l'Ajuntament va sollicitar al capítol catedralici fer una rogativa extraordinària i exposar el Santíssim Sagrament. ${ }^{20} \mathrm{~A}$ partir d'aquest moment totes les rogatives que es van fer tenien caràcter extraordinari i s'havien produït en ocasions molt singulars d'extrema necessitat. La tarda del 26 d'abril es va citar tots els veïns a la catedral per apellar al Santíssim Sagrament. Normalment els oficis de rogatives es duien a terme en un moment concret del dia, però en aquest cas el capítol va decretar rogatives després de nones, vespres, completes i matines. ${ }^{21} \mathrm{Com}$ a últim recurs es va decidir convocar rogatives en tots els convents de la ciutat el dia 1 de maig. ${ }^{22}$ Finalment, el dia 5 es va ordenar cancellar tots els actes perquè havia plogut. ${ }^{23}$

En el cas de Barcelona les rogatives van començar el 21 de gener. ${ }^{24}$ A mesura que s'accentuava la falta d'aigua, aquestes rogatives van anar adquirint un caràcter més extraordinari, fins a la successió de processons generals amb les relíquies i imatges d'alguns dels

16. Vegeu un estudi que permet comparar aquesta sequera amb una anàlisi quantitativa dels processos de rogatives a Espanya (1750-1850) a Domínguez-Castro et al. (2012). Per a Portugal, vegeu Pedro (2020).

17. Arxiu Històric de la Ciutat de Tarragona (AHCT), Actes Municipals (AM), 1817, Actes, f. 17.

18. AHCT, AM, 1817, Actes, f. $23 v$.

19. AHCT, AM, 1817, Correspondència, f. 87-88.

20. AHCT, AM, 1817, Actes, f. 43.

21. AHCT, AM, 1817, Correspondència, f. 133-134.

22. AHCT, AM, 1817, Correspondència, f. 139.

23. AHCT, AM, 1817, Actes, f. 50.

24. Arxiu Històric de la Ciutat de Barcelona (AHCB), Acords, 1817, f. $13 v$. 
sants i les patrones més importants de la ciutat. ${ }^{25}$ Podem dir que aquests actes van passar a formar part de la vida diària dels barcelonins durant els prop de cinc mesos que va durar la sequera. Es van començar a celebrar rogatives diàries a la catedral, ${ }^{26}$ que van condicionar l'organització de la Setmana Santa ${ }^{27}$ i van originar disputes entre les autoritats, com quan el governador es va proposar suspendre les rogatives durant la celebració del carnestoltes, fet que va originar l'oposició de l'Ajuntament, que era del parer de suspendre les diversions públiques mentre duressin les rogatives. ${ }^{28}$ Una mostra de la dramàtica situació viscuda durant aquests mesos és el memoràndum presentat pel gremi de pagesos a l'Ajuntament a finals de juny, on es fan palesos el seu tedi i la seva resignació. El gremi dona gràcies a la providència per haver plogut, tot i que «en veritat no va ser suficient per a la sequedat que tenia la terra, i com l'estació present no dóna esperances de pluja, són del parer sent de l'agradi de V.S. el que podrien tornar a les seves respectives esglésies i convents la imatge de N. S. de la Mercè i les relíquies de la Santa Matrona». ${ }^{29}$

A Girona les rogatives es van iniciar poc abans que a Tarragona i Barcelona, concretament el 25 de desembre de 1816. A finals de gener hi va haver pluges esporàdiques i es va plantejar posar fi a les rogatives, però la insistència del gremi de pagesos que aquestes pluges havien estat insuficients per palliar la urgent necessitat dels camps va propiciar que les rogatives continuessin. El capítol catedralici va organitzar rogatives el 5 de febrer amb l'exposició del Santíssim Sagrament i el 26 de febrer la confraria de la Puríssima Sang va anunciar la seva intenció d'organitzar una processó per tota la ciutat. Molts d'aquests actes no s'havien celebrat des de la sequera de 1788, que va contribuir a una crisi de subsistència de gran abast amb episodis tan coneguts com els Rebomboris del Pa de 1789 a Barcelona. La mateixa confraria va recopilar una memòria de totes les rogatives en què va participar des de finals de febrer fins a mitjan maig, període que ve a coincidir amb el procés de rogatives que hem pogut estudiar a Tarragona i Barcelona. Finalment, el 9 de maig s'anuncià la intenció de posar fi a les rogatives, el dia 11 se celebrà un ofici per donar gràcies per l'arribada de les pluges i el dia 15 va tenir lloc la processó per tornar a la seva capella el Sant Crist de la confraria de la Puríssima Sang. ${ }^{30}$

\section{Mirant al cel. Les conseqüències de la sequera}

Quines van ser les conseqüències d'aquesta sequera? Els seus efectes semblen evidents, per exemple, en l'augment del preu del gra i l'increment de les importacions. Un simple cop d'ull al preu del blat a Barcelona entre 1814 i 1867 ens permet observar que durant el Sexenni el preu va ser notablement superior a la mitjana, i va ser l'any 1817 quan es va re-

25. AHCB, Acords, 1817, f. 51 i $72 v$.

26. AHCB, Acords, 1817, f. 200.

27. AHCB, Acords, 1817, f. 91.

28. AHCB, Acords, 1817, f. 49.

29. AHCB, Acords, 1817, f. 220.

30. Arxiu Municipal de Girona (AMG), Actes Municipals (AM), 1817. 
gistrar un dels increments més importants de tot aquest període de cinquanta anys (Segura 1983: 212). Durant aquest any també es va produir un notable increment en l'entrada d'embarcacions mercants a Barcelona, signe inequívoc de l'augment de les importacions (Barriendos i Dannecker 1999: 57-58). Tenim altres exemples sobre aquesta urgent necessitat d'importar gra, com a Tarragona:

Noticioso de la escasez de trigos que hay en este Principado de Cataluña desea acarrear dicho género, pero necesitando para las compras, del correspondiente certificado del respectivo Ayuntamiento del pueblo a donde quiere introducir el trigo. ${ }^{31}$

En el cas de la ciutat de Girona, podem observar que entre els anys 1814 i 1830 els preus més alts d'alguns productes com el blat, l'ordi, el mill, la civada i el blat de moro es van registrar els anys 1815-1818 (Simón Tarrés 1985: 167-168). Més enllà del nord-est peninsular, hi ha estudis que demostren que el repunt en els preus dels grans durant l'any 1817 va ser un fenomen global (Post 1977: 37). El descens dels preus a Europa durant els anys posteriors a les guerres napoleòniques ha estat àmpliament estudiat per historiadors com Josep Fontana, qui descriu un descens dels preus agraris que va afectar de manera desigual els diferents països europeus en funció de la capacitat de resposta de la seva producció agrària. Així doncs, mentre que a la Gran Bretanya i França s'havien introduït nous mètodes que havien reduit els costos i millorat la producció, fets que minimitzaren els efectes de la crisi, a Espanya els camperols produien el mateix i ho venien més barat (Fontana 2002: 32). No obstant això, aquest descens dels preus no començà a ser important fins al 1818, després de la sequera del 1817. De fet i com ja hem avançat, els preus agraris van experimentar un increment gradual durant els anys 1815-1817, i és en aquest darrer quan es va registrar un dels increments més importants en els índexs de preus agraris de tota la primera meitat del segle xix. Així doncs, aquest descens es va concentrar en els anys 1818-1819, moment en què els preus agraris espanyols van arribar a caure més d'un 40\% respecte a la mitjana dels cinc anys anteriors (Fontana 2002: 73; Fontana 1979: 262; Torras 1985: 159).

Durant el primer terç del segle xIx també es van succeir diverses epidèmies que en molts casos han passat desapercebudes perquè van coincidir amb anys de conflicte armat. ${ }^{32}$ Els brots més importants a Catalunya es van produir durant l'any 1809, en plena Guerra del Francès. Al Camp de Tarragona aquest any va ser conegut com l'«any de les malalties» a causa d'un brot de tifus. En aquesta regió la mortalitat registrada l'any 1809 va representar el 17\% de la mortalitat del període 1801-1820. Més enllà de la crisi d'aquest any, que va afectar bona part de Principat, sabem que aquests brots s'anaren succeint a la fi del Sexenni, més concretament els anys 1817, 1819 i 1820 (Güell 2011: 198-207).Aquestes epidèmies,

31. AHCT, AM, 1817, Correspondència, f. 194.

32. Tot i que les darreres publicacions aparegudes durant la commemoració del bicentari fan un esforç per contextualitzar i analitzar les conseqüències d'aquestes epidèmies. Segons els últims estudis, es calcula que les fams i epidèmies van causar dues terceres parts de la mortalitat registrada durant la Guerra del Francès a Catalunya (Arnabat 2013: 147). 
que, com hem vist, van ser recurrents durant aquests anys, van originar una gran preocupació entre les autoritats, que s'afanyaren a prendre mesures i evitar la seva propagació. L'any 1817 es va produir un brot de pesta a Alger que es va propagar ràpidament per alguns ports italians. I a l'octubre apareixia aquesta notícia al Diari de Barcelona:

Ayer fondeó en este lazareto la goleta inglesa, nombrada Princesa Carlota, del mando del capitán Juan Midini, procedente de Argel con cinco días de navegación. El referido capitán ha declarado que continua la peste de aquella capital, de la que mueren de 30 a 40 personas cada día. ${ }^{33}$

Durant aquest mateix mes d'octubre Ferran VII va signar un reial decret on instava les juntes de sanitat i les principals ciutats portuàries a prendre mesures per evitar la propagació de la pesta per la Península. ${ }^{34}$ Finalment, el desembre de 1817 la monarquia va ordenar l'establiment de cordons sanitaris i la quarantena per a totes les embarcacions procedents d'Alger. Aquest no va ser un cas aillat, ja que anteriorment, el gener de 1816, la monarquia també va decretar la quarantena obligatòria a Menorca de les embarcacions procedents de Llevant que volguessin desembarcar a les costes espanyoles, a causa de la notícia dels continus rebrots de pesta que s'hi estaven succeint. La mesura va contribuir a dificultar l'arribada de les grans quantitats de gra que s'estaven important des del mar Negre en aquest moment de necessitat (Valenciano 2012: 97). Les reiterades epidèmies van donar lloc a una major conscienciació per implementar mesures higièniques. En el cas de Barcelona, per exemple, l'any 1815 el regidor Marià de Cabanes va plantejar una proposta per a la recollida de brossa (Arnabat i Solà 2008: 29). Durant aquests anys, l'Ajuntament, a instància del corregidor, també va insistir els veïns que mantinguessin nets els portals i els reguessin per palliar la sequedat de l'ambient (Pometti 2020).

La manca d'aigua també va donar lloc a conflictes pel dret al seu accés i ús, com a Tarragona. La ciutat es trobava dividida en dos nuclis de població: la part alta i el barri marítim o zona del port. Els habitants d'aquest últim tenien dret a accedir a la sèquia de la part alta un cop cada cinc dies per regar els seus cultius, fet que va originar tot un seguit de disputes que van acabar amb la mediació de l'Ajuntament quan els habitants de la part alta es van negar a facilitar l'accés a la sèquia als habitants del port. Un fet semblant va ocórrer a Girona quan els municipis de Santa Eugènia de Ter i Salt van presentar una queixa al governador davant els abusos del batlle d'aigües, qui els negava l'accés a la sèquia Monar, situada al nord de la ciutat, esgrimint privilegis i drets privatius. L'Ajuntament també va denunciar que molts pagesos embussaven els canals per augmentar el cabal de reg de les seves terres. La manca d'aigua a la sèquia Monar era un assumpte que preocupava les autoritats i els diversos collectius que depenien d'aquesta, com els arrendataris dels molins fariners, que van exercir una forta pressió perquè es limités l'accés a la sèquia. El 20 de maig es va publicar un llistat d'obligacions per a tots els que tinguessin terres pròximes a la sèquia i els canals, com garantir la neteja de la llera i no extreure aigua sense l'autoritza-

33. Diari de Barcelona, 23 d'octubre de 1817, p. 2.

34. Decretos del rey Don Fernando VII (1817). 1818, vol. iv, 524. 
ció prèvia. Durant aquests mesos també es pot observar un interès especial per les obres que s'estaven realitzant a la llera del riu Ter. N'és un exemple la denúncia de l'Ajuntament sobre un canal que s'estava construint al riu al municipi d'Anglès, $15 \mathrm{~km}$ al nord-oest de Girona. Es considerava que aquest canal era molt poc eficient, ja que el terreny era molt porós i, per tant, una part important de l'aigua es filtraria al subsol. ${ }^{35}$

També conservem relats de com la sequera va originar dificultats a l'hora de moldre el gra, ja que molts dels molins funcionaven amb energia hidràulica. A Arenys de Munt tots els molins de la zona van quedar inoperants, fins al punt que es va haver de portar el gra a Girona (a 60 km) o es van haver d'utilitzar dos molins d'emergència conduïts per persones i cavalls (Trigo et al. 2009: 103).

A la ciutat de Barcelona l'escassetat d'aigua també va originar una major conscienciació per optimitzar-ne la gestió. Es van començar a netejar les sèquies i la xarxa de canalitzacions de la ciutat, en gran part deteriorada pels estralls de la guerra i la qual pràcticament no havia rebut cap atenció des de llavors. La sequera del 1817 va donar lloc a algunes mesures de racionament: a finals de març, per exemple, es va acordar reduir el cabal d'aigua destinat a les cases de la Reial Audiència per poder garantir el subministrament de les fonts públiques de la ciutat. ${ }^{36} \mathrm{Ja}$ des de finals d'abril els talls en els canals que emanaven del riu Besòs van començar a ser cada vegada més freqüents ${ }^{37}$ i el 22 d'abril s'informava que ja no quedava aigua al rec Comtal (Pometti 2020).

Davant la sequera que es va produir durant aquests anys es va fer palesa la necessitat de buscar noves fonts d'abastiment que compensessin la manca de pluja. A Tarragona en tenim un exemple molt illustratiu. Jaume Parcet, cirurgià de marcada tendència liberal i futur alcalde de la ciutat l'any 1839, va decidir presentar a l'Ajuntament un memorial titulat «Dissertació hidràulica sobre la font de l'Arrabassada» l'any 1817, on plantejava recuperar una font natural que moria en una de les platges de la ciutat. En aquest text, Parcet analitza la composició de l'aigua i conclou que no és potable a causa de l'entrada d'aigua salada. Així doncs, proposa intentar accedir a la font terra endins per trobar aigua dolça en un punt anterior a la seva trobada amb l'aigua del mar. En el memorial l'autor insisteix en la necessitat d'explotar aquest i altres possibles pous i deus per poder garantir el subministrament dels cultius de la zona. ${ }^{38}$ Aquesta no fou un cas aillat, ja que a finals del 1817 el mateix Ajuntament va recomanar al governador aprovar la sollicitud d'uns particulars per construir una mina subterrània en un dels turons limítrofs a la ciutat, ja que «de tal concessió no pot seguir-se perjudici algun al públic ni a tercer, abans si gran benefici si es troba aigua». ${ }^{39}$

35. AMG, AM, 1817.

36. AHCB, Acords, 1817, f. $93 v$.

37. AHCB, Acords, 1817, f. 160.

38. AHCT, AM, 1817, Correspondència, f. 174-175.

39. AHCT, AM, 1817, Actes, f. 138. 


\section{La fam del 1817}

Les males collites d'aquests anys van originar una crisi de subsistència que es va acabar materialitzant durant l'any 1817. Molts dels habitants de les zones rurals que havien perdut les seves collites i havien quedat abocats a la indigència es van dirigir a les grans ciutats a la recerca d'almoina. Ciutats com Girona van haver de fer front a l'arribada d'aquests indigents. Finalment la situació es va tornar insostenible i a mitjan abril l'Ajuntament va proposar l'organització d'una junta de caritat:

En atención a que de resultas de la carestía general se van amontonando pobres en esta ciudad y que sin embargo de que las personas caritativas que les asisten en las puertas de sus casas no consiguen el fin de que se remedie la necesidad en general, y considerando que en semejante lance lo mejor es que se forme una Junta de Caridad [...] la que se dedicase a discurrir medios para la formación de una olla patriótica. ${ }^{40}$

El 16 de maig es va començar a repartir aquesta olla patriòtica, altres vegades dita econòmica, alhora que s'amenaçava de tancar a la presó tots els que actuessin com a captaires a la ciutat. L'olla va durar poc més d'un mes, ja que els fons obtinguts de la beneficència dels veïns es van acabar ràpidament a causa de les prop de nou-centes persones que es podien arribar a assistir en un mateix dia. A més, el governador era contrari a aquest tipus de mesures, que a parer seu afavorien la ganduleria, i va acabar demanant als veïns que se centressin a atendre els impedits i deixessin de banda els captaires.

A Barcelona les autoritats també van haver de gestionar aquesta crisi, amb denúncies per part dels veïns davant un augment considerable del preu del pa, fet que va despertar una preocupació creixent a l'Ajuntament a causa de la dificultat de posar-hi solució, ja que aquest augment de preu es devia a les dificultats per moldre el blat per la falta d'aigua en bona part dels molins de la ciutat. ${ }^{41}$ Les revoltes del 1789 encara estaven molt presents i a finals d'abril es va començar a plantejar seriosament l'opció de recuperar diversos molins fariners de tracció animal. Durant els dies posteriors l'Ajuntament es va centrar a buscar locals per establir aquests molins provisionals $i$, després de conèixer que alguns particulars n'estaven muntant per fer negoci, va ordenar que s'obrissin tots els molins disponibles a la ciutat sense cap tipus de cost per al públic. ${ }^{42}$ També es va arribar a plantejar, encara que fos temporalment, la prohibició d'extreure farina de la ciutat. ${ }^{43}$

Tot sembla indicar que hi va haver dues onades de migració camp-ciutat: aquesta primera que acabem de descriure i que s'ajusta als mesos en què la sequera fou més severa (abril-maig), i una segona onada que va començar a cobrar força a partir del mes de setembre amb la constatació de la pèrdua d'una part importat de les collites. En el cas de Barcelona, per exemple, el dia 5 d'octubre el governador va manar publicar una normativa re-

40. AMG, AM, 1817.

41. AMG, AM, 1817.

42. AHCB, Acords, 1817, f. 165.

43. AHCB, Acords, 1817, f. 162. 
lativa a les gents que s'havien amuntegat a la ciutat com a conseqüència de la sequera i la pèrdua de les collites. El text mostra una ciutat saturada, totalment superada per la situació, i donava un termini de vint-i-quatre hores perquè totes les famílies que no tinguessin el seu domicili a Barcelona abandonessin la ciutat. Algunes de les mesures incloïen multes per als que recollissin gent a casa seva o l'empresonament de tots els que demanessin almoina. ${ }^{44}$

Fins ara hem fet una aproximació a com van reaccionar les ciutats a l'arribada d'aquestes masses procedents del camp, però també tenim relats de com es va viure aquesta sequera a les regions rurals d'origen. L'estudi de la Companyia de Cortadelles ens ha permès identificar la dramàtica situació que es va viure a l’Urgell:

Faltan el agua para moler y aun para beber de forma que pueblos enteros de la comarca de Urgell quedan abandonados por sus habitantes, que andan mendigando a bandadas por la provincia, y los propietarios pudientes de lugares cortos van a establecerse en los grandes para estar más a cubierto de insultos. ${ }^{45}$

Aquestes bandes formades per marginats i vagabunds van intentar saquejar alguns graners, i pobles com el Poal es van plantejar tancar les seves portes, mesura que ja havien adoptat altres municipis de la regió. ${ }^{46} \mathrm{La}$ Companyia va començar a vendre gra per por que la multitud assaltés els graners, mentre que durant els anys previs, tot i les males collites, s'havia dedicat a especular i vendre el gra quan el seu preu registrava el punt més alt. Aquesta por sembla estar justificada, ja que circulaven notícies de la formació de quadrilles que anaven a la recerca de graners i a la caça de les autoritats. ${ }^{47}$

Per combatre aquesta situació es van prendre diverses mesures, com ara la creació, a Lleida, d'una junta de beneficència que tenia l'objectiu de palliar els efectes de les males collites i la manca de grans (Sánchez Carcelén 2007: 194). La Junta va demanar grans a la Companyia, que només es va decidir a aportar-ne amb la condició que es vigilés que es dediquessin a la sembra, i no al consum. ${ }^{48}$ Els senyors també van donar facilitats als pobles, com ara reduir les recaptacions perquè es pogués utilitzar el gra per sembrar. En general, podem afirmar que aquesta regió va encadenar anys de fam i males collites, però el seu apogeu va ser la sequera del 1817:

La miseria extrema en la que se hallan los pueblos de la baronía de Bellpuig así como todos los de la comarca de Urgell tiene su primer origen en la desastrosa última guerra en la que quedaron sin caballerías ni granos y con una gran porción de tierras incultas. Cuando empezaban a reponerse con las dos primeras cosechas después de la paz que fueron medianas se han seguido otras dos fatales y la última en tanto grado a causa de la sequía que ni han llegado a coger las simientes que habían sembrado habiéndoles

\footnotetext{
44. Diari de Barcelona, 5 d'octubre de 1817.

45. AHT, CA, Cartes, 1817, f. 520.

46. AHT, CA, Cartes, 1817, f. 868.

47. AHT, CA, Cartes, 1817, f. 422.

48. AHT, CA, Cartes, 1817, f. 1021.
} 
fallado también tres años la del aceite que es de alguna consideración. De resultas se hallan inundadas las calles y plazas de esta ciudad y los caminos públicos del principado de propietarios antes acomodados y de jornaleros del Urgell con sus familias que por no tener trabajo ni de que subsistir andan pidiendo limosna después de haber abandonado sus hogares, y así es que no hay pueblo en la Baronía en que no se vean cerradas muchas casas, y si en este año no acuden las lluvias para la sementera va a quedar despoblada la comarca de Urgell como ya lo ha estado en otros siglos por iguales causas: y aunque el cielo les favorezca con el beneficio de la lluvia si no encuentran granos parar sembrar, quedara también despoblada la mayor parte de aquel territorio. ${ }^{49}$

Veiem que hi havia una gran preocupació no ja per la pèrdua de les collites, sinó per la falta de sements que encadenessin males collites durant els anys següents. També resulta evident la por de les autoritats a possibles revoltes populars en un context que era del tot propici a aquestes. ${ }^{50}$ Una de les fórmules adoptades tradicionalment per intentar calmar els ànims era donar treball i mantenir ocupats els qui havien perdut les collites. Així, durant aquests anys, tot i la greu crisi econòmica, es van promocionar tot un seguit d'obres públiques, com ara la carretera entre Lleida i Tarragona, les obres de la qual començaren el setembre del 1817 (Rovira 1985), o la planificació del canal d'Urgell també durant aquest mateix any, que havia de garantir el reg de tota aquesta regió que tant havia patit en aquests últims anys (Llobet 2009: 455-465). A finals d'abril, per exemple, el capità general va manar a l'Ajuntament de Barcelona que elaborés un informe referent a les tasques disponibles amb les quals es podria donar feina als nombrosos desocupats que s'amuntegaven a la ciutat. ${ }^{51}$ Són molts els exemples que podríem esmentar. El mateix capità general, Francisco Javier Castaños, va ser un dels principals promotors del canal d'Urgell i del canal de la Infanta, al Llobregat, que també es va començar a construir durant l'any 1817. Un dels enginyers que van participar en la projecció de canal de la Infanta va ser Agustí Canelles, conegut per denunciar davant les autoritats militars la necessitat d'elaborar una carta cartogràfica de tot Catalunya que acabés sent l'eix a partir del qual es projectessin canals de reg per tot el Principat i així es pogués garantir el reg dels camps (Hernando 2008: 415).

\section{Conclusions}

El Sexenni Absolutista va ser un període de conflictivitat social, de resistència al pagament de les rendes senyorials i de greu crisi econòmica. El fet que el règim absolutista collapsés com a conseqüència de la inviabilitat de les seves polítiques no implica que fenòmens conjunturals com la sequera que es donà durant aquest període i la crisi de subsistència del

49. AHT, CA, Cartes, 1817, f. 1065.

50. Tot $\mathrm{i}$ que en aquest article ens centrem en l'Urgell i Catalunya, existeixen evidències que aquest context de males collites i fam va originar un increment de la conflictivitat al món rural a la resta del territori espanyol, com, per exemple, a Navarra (De la Torre 1990: 29).

51. AHCB, Acords, 1817, f. 165. 
1817 que hem presentat en aquest article no tinguessin també una importància en el malestar de la població. Amb aquest treball pretenem aportar claror sobre aquesta sequera i la irregularitat climàtica d'aquests anys per tal de poder entendre millor la crisi del Sexenni Absolutista. La sequera va causar estralls en ciutats com Girona, Barcelona i Tarragona, on els ajuntaments i les autoritats van tenir diferents reaccions davant la gravetat de la situació i les particularitats de cada ciutat. A Tarragona hem destacat el cas de Jaume Parcet com a paradigma de la necessitat de buscar noves fonts d'aigua amb què poder regar els camps. En el cas de Barcelona va existir un problema evident davant la dificultat de moldre el gra a causa de la dependència dels molins d'acció hidràulica, al qual l'Ajuntament respongué establint molins provisionals de tracció animal que es van distribuir per diferents punts de la ciutat. La sequera també va originar una major conscienciació per mantenir en bon estat el sistema de canalitzacions i es van haver de fer alguns talls per garantir el subministrament a les fonts públiques. Val a dir que, avui dia, el 1817 continua sent l'any amb el valor de precipitació total anual més baix mai registrat a la ciutat de Barcelona (Barriendos i Dannecker 1999: 56), tres vegades inferior a la mitjana dels anys 1786-1996 (Barriendos 2005: 26). ${ }^{52}$ A Girona la dependència del riu Ter per abastir la ciutat va originar que l'Ajuntament intentés estar al corrent de les obres de canalització que es van fer en el seu curs durant aquesta època, amb l'objectiu de garantir el màxim cabal possible en la seva arribada a la ciutat.

També hem intentat aproximar-nos a la realitat viscuda per aquestes famílies de pagesos que van haver d'abandonar els seus camps erms i dirigir-se a les ciutats fugint de la fam. L'exemple de l'Urgell resulta del tot representatiu. Hem pogut rastrejar l'arribada d'aquestes masses a algunes de les principals ciutats de Catalunya, així com la resposta de les diferents autoritats, l'organització de juntes de caritat i la creació d'olles patriòtiques. Moltes d'aquestes mesures es van veure ràpidament exhaurides i sobrepassades a causa del gran nombre de persones a les quals calia atendre. Arribats a aquest punt, en el qual semblava evident que la ciutat no era capaç d'absorbir aquestes masses de població, les autoritats van començar a decretar la seva expulsió, tal com hem vist en el cas de Barcelona. D'altra banda, també hem pogut tractar la por d'aquestes autoritats al fet que aquest context de males collites i fam desencadenés revoltes. La promoció d'obres públiques durant aquest període de greu crisi econòmica havia de contribuir a mantenir aquestes masses ocupades $\mathrm{i}$ evitar que deambulessin sense rumb o se sumessin a bandes de tumultuosos i saquejadors.

En altres períodes més estudiats, com el Trienni Liberal, aquestes catàstrofes naturals (com les sequeres de 1821 i 1822 o la febre groga de 1821) sí que s'han tingut més en compte a l'hora de contextualitzar la crisi de subsistència que va assolar el territori espanyol durant aquesta època. Aquests fenòmens de caràcter conjuntural van contribuir al malestar social, que va enrarir i dificultar l'acció de govern liberal..$^{53}$ De la mateixa manera, aquestes

52. De fet, les dades instrumentals més antigues d'Espanya van ser recollides per Francisco Salvá a Barcelona. Aquestes dades es van recuperar fa relativament poc i es poden consultar a: Prohom, Barriendos, Sánchez-Lorenzo (2015).

53. La sequera $\mathrm{i}$ les males collites de 1822 van originar un increment d'entre el $30 \mathrm{i}$ el $40 \%$ del preu del blat, en un moment en què els jornals havien disminuït un 40\% a Catalunya (Arnabat 2001: 201). 
catàstrofes naturals van adquirir un significat singular durant el Trienni, ja que van ser identificades com un càstig diví contra les polítiques liberals pels ultres i una part de la jerarquia eclesiàstica. És a dir, es van instrumentalitzar com a arma política. L'estudi d'aquest fenomen podria tenir encara recorregut, a ajudar-nos a entendre fins a quin punt va poder calar aquest discurs entre les classes populars, especialment en el món rural: ${ }^{54}$

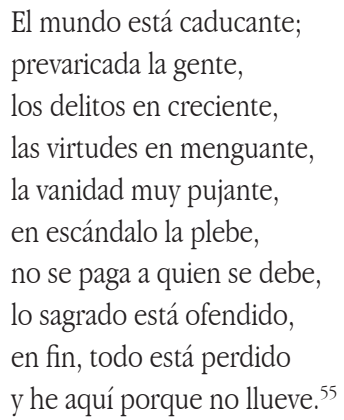

\section{Referències bibliogràfiques}

ARnABAT, Ramon (2001). La revolució de 1820 i el Trienni Liberal a Catalunya. Vic: Eumo. Arnabat, Ramon (2004). Liberals i reialistes. El Trienni Liberal al Penedès, 1820-1823. 2a ed. Vilafranca del Penedès: Institut d'Estudis Penedencs.

Arnabat, Ramon (2013). «Les Postguerres del Francès». Dins R. Arnabat. La Guerra del Francès 200 anys després. Tarragona: Publicacions URV.

Arnabat, Ramon; Solà, Àngels (2008). «L'Ajuntament de Barcelona (1808-1839)». Dins M. RisQues (dir). Història de l'Ajuntament de Barcelona. Vol. II. Barcelona: Ajuntament de Barcelona / Enciclopèdia Catalana, p. 18-51.

ARTola, Miguel (1959). Los orígenes de la España contemporánea. Madrid: Instituto de Estudios Políticos.

Artola, Miguel (1968). «La España de Fernando VII». Dins R. MenÉndez Pidal. Historia de España. Madrid: Espasa-Calpe, p. 32.

BARriendos, Mariano (2005). «Variabilidad climática y riesgos climáticos en perspectiva histórica. El caso de Catalunya en los siglos XVIII-XIX», Revista de Historia Moderna, núm. 23, p. 11-33.

54. Historiadors com Josep Fontana han criticat les carències evidents d'aquest discurs, ja que durant els primers anys de la Dècada Ominosa també es produïren importants sequeres i males collites (Fontana 2006: 121-122). Que aquest discurs fos fallaç no implica que no hagués pogut calar entre les classes populars en un moment en què l'Església conservava una important capacitat d'influència social.

55. Poblet 1980: 101-102. 
Barriendos, Mariano (1996). «El clima histórico de Catalunya (siglos XIV-XIX). Fuentes, métodos y primeros resultados», Revista de Geografía, núm. 30, p. 69-96.

Barriendos, Mariano; Dannecker, Andreas (1999). «La sequía de 1812-1824 en la costa central catalana. Consideraciones climáticas e impacto social del evento». Raso, J. M.; MarTíN-VIDE, J. (eds). La climatología española en los albores del siglo XXI: Aportaciones presentadas al I Congreso de la Asociación de Climatología. Barcelona: Publicaciones de la Asociación Española de Climatología, p. 53-61.

Barriendos, M.; Prohom, M.; Sánchez-Lorenzo, A. (2010). «Extreme drought condicitions over NE Iberia in early 19th century (1812-1825) and its possible relationship to major volcànic eruptions», EGUGA, vol. 12, p. 4926.

Briffa, K.R.; Schweingruber, F.H.; Osborn, T.J (1998). «Influence of volcanic eruptions on northern hemisphere summer temperature over the past 600 years», Nature, núm. 393, p. $450-455$.

Briffa, K.R.; Schweingruber, F.H.; Osborn, T.J. (2004). «Large-scale temperature inferences from tree rings, a review», Global and Planetary Change, vol. 40, núm. 1-2, p. 1126.

Decretos del rey Don Fernando VII. Recopilats per Fermín Martín de Balsameda. Vol. Iv. Madrid: Imprenta Real, 1817.

Domínguez-Castro, Fernando et al. (2012). «Assessing extreme droughts in Spain during 1750-1850 from rogation ceremonies», Climate of the Past, núm. 8, p. 705-722.

Fischer, Erich et al. (2007). «European climate response to tropical volcanic eruptions over the last half millennium», Geophysical Research Letters, núm. 4-5, p. 1-6.

Fontana, Josep (1961). La Revolució de 1820 a Catalunya. Barcelona: Rafael Dalmau.

Fontana, Josep (1973). Hacienda y Estado en la crisis final de Antiguo Régimen español, 1823-1833. Madrid: Instituto de Estudios Fiscales.

Fontana, Josep (1979). La crisis del Antiguo Régimen 1808-1833. Barcelona: Crítica.

FonTANa, Josep (2002). La quiebra de la monarquía absoluta (1814-1820). Reed., ed. or. de 1971. Barcelona: Ariel.

FonTANa, Josep (2006). De en medio del tiempo: La segunda restauración española 18231834. Barcelona: Crítica.

FonTana, Josep (2008). La Guerra del Francès (1808-1814). Barcelona: Pòrtic.

Forn i Salvà, Francesc (1997). «Fer ploure a l'Antic Règim», Sessió d'Estudis Mataronins, núm. 14, p. 127-140.

Garza, Gustavo; Barriendos, Mariano (1998). «El Clima en la historia», Ciencias, núm. 51, p. 22-25.

Gil Novales, Alberto (1980). Reed.: 2020. El Trienio Liberal. Madrid: Siglo XXI.

Grau i Pujol, Josep M. (1990). «Les rogatives i altres notes sobre Alcover (ss. XvIII-XIX)», Butlleti del Centre d'Estudis Alcoverencs, núm. 51, p. 14-27.

GüELL, Manel (2011). La crisi de la Guerra del Francès (1808-1814) al Camp de Tarragona. Tarragona: Cercle d'Estudis Guillem Oliver.

Hamnet, Brian (1985). La política española en una época revolucionaria (1790-1820). Ciutat de Mèxic: FCE. 
Harington, Charles R. (1992). The year without a summer? Ottawa: Canadian Museum of Nature.

Hernando, Agustín (2008). «Reducir la complejidad territorial a la claridad del mapa: Agustí Canelles y su propuesta de reconocimiento de Cataluña (1816)», Treballs de la Societat Catalana de Geografia, núm. 65, p. 417-428.

LA PARRA, Emilio (2018). Fernando VII, un rey deseado y detestado. Barcelona: Tusquets.

LeE, Debora; MackenzIE, A. R. (2010). «Trans-hemispheric effects of large volcanic eruptions as recorded by an early 19th century diary», International Journal of Climatology, núm. 30-14, p. 2217-2228.

LLOBET, Josep Maria (2009). «Documents relacionats amb la construcció dels canals d'Urgell (1817-1819)», URTX, núm. 23, p. 455-465.

Lough, Janice (1992). «Climate in 1816 and 1811-20 as Reconstructed from Western North American Tree-Ring Chronologies». Dins C. R. HARINGTON. The year without a summer? Ottawa: Canadian Museum of Nature, p. 97-114.

Lus, Jean-Philippe (2002). L'utopie réactionnaire, épuration et modernisation de l'Etat dans l'Espagne de la fin de l'Ancien Régime (1823-1834). Madrid: Casa de Velázquez. Moliner Prada, Antoni (2007). Catalunya contra Napoleó: La Guerra del Francès 18081814. Lleida: Pagès.

Oppenheimer, Clive (2003). «Climatic, environmental and human con sequences of the largest known historic eruption, Tambora volcano (Indonesia) 1815», Progress in Physical Geography, núm. 27-2, p. 230-259.

París, Álvaro (2016). Se susurra en los barrios bajos, Policía, opinión y política popular en Madrid, 1825-1827 (Tesi doctoral). Madrid: Universidad Autónoma de Madrid.

Pedro, Luis (2020). «Climate and crops in northwest Portugal (1798-1830): A glimpse into the past by the light of two Benedictine diaries», Historia Agraria, núm. 82, p. 99-139.

PoвıEт, Josep M. (1980). Josep Robrenyo: Comediant, escriptor i revolucionari (1783-1838). Barcelona: Millà.

Pometтr, Kevin (2020). «Fiebres, salubridad e inestabilidad ambiental en el contexto de la Megadrought: el caso de Barcelona (1815-1818)», Amnis, núm. 19.

PosT, John D. (1977). The last great subsistence crisis in the western world. Baltimore: The Johns Hopkins University Press.

Prohom, Marc; Barriendos, Mariano; Sánchez-Lorenzo, Arturo (2015). «Reconstruction and homogenization of the longest instrumental precipitation series in the Iberian Peninsula (Barcelona, 1786-2014)», Internacional Journal of Climatology, núm. 36, p. 3072-3087. Rовоск, Alan (2000). «Volcanic Eruptions and Climate», Reviews of Geophysics, núm. 38-2, p. 191-219.

RocA, Jordi (2011). La Barcelona revolucionària i liberal: exaltats, milicians i conspiradors. Lleida: Pagès / Fundació Noguera.

RoviRA, Salvador (1985). «Els orígens de la carretera Tarragona-Lleida: 1804-1820», Revista Tècnica de la Propietat Urbana, núm. 34, p. 103-116.

Rújula, Pedro (1998). Contrarevolución: Realismo y carlismo en Aragón y el Maestrazgo. Saragossa: Prensas Universitarias de Zaragoza. 
Salvat i Bové, Juan (1965). Tarragona en la Guerra y en la Postguerra de la Independencia. Tarragona: Reial Societat Arqueològica Tarraconense.

SALES, Núria (1983). «Ramblers, traginers i mules (s. XVIII-XIX)», Recerques, núm. 13, p. 65-81.

Sánchez Carcelén, Antoni (2007). Absolutisme i liberalisme a Lleida. 1814-1828 (Tesi doctoral). Lleida: UdL.

SAUCH, Núria (2011). La Guerra del Francès als territoris de parla catalana. Catarroja: Afers.

SEGURA, Antoni (1983). «El mercat de cereals i llegums a Barcelona, 1814-1868», Recerques, núm. 14, p. 177-212.

Simón TARrés, Antonio (1985). La crisis del Antiguo Régimen en Girona. Barcelona: UAB.

Tello, Enric (2005). La bistoria cuenta: Del crecimiento económico al desarrollo bumano sostenible. Barcelona: El Viejo Topo.

TORRAs, Jaume (1976). Liberalismo y rebeldía campesina. Barcelona: Ariel.

TORRAS, Jaume (1985). «Aguardiente y crisis rural. Sobre la coyuntura vitícola, 1793-1832».

Dins A. García Sans i R. Garrabou. Historia agraria de la España contemporánea. Barcelona: Crítica, p. 151-173.

TORRe, Joseba de la (1990). «Crisis de una economía agraria y respuestas campesinas en la quiebra del antiguo régimen. Navarra, 1808-1820», Revista de Historia Económica, núm. 8, p. 11-35.

TRigo, Ricardo et al. (2009). «Iberia in 1816, the year without a summer», Internacional Journal of Climatology, núm. 29-1, p. 99-115.

Valenciano, Valentí (2012). El Trienni Liberal a Mallorca (1820-1823) (Tesi doctoral). Mallorca: UiB.

VINAIXA, Joan (1998). La Postguerra del Francès i la revolta reialista de 1822 a l'Ebre. Barcelona: Columna.

WAGNER, Sebastian; ZoriTA, Eduardo (2005). «The influence of volcanic, solar and CO2 forcing on the temperatures in the Dalton Minimum (1790-1830). A model study», Climate Dynamics, vol. 25, núm. 2-3, p. 205-218. 